\title{
Experimental Phase Diagram Study of the Fe-Ni-Te System
}

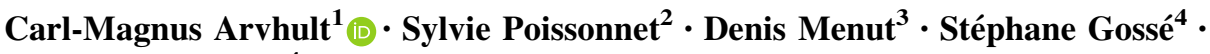 \\ Christine Guéneau ${ }^{4}$
}

Submitted: 8 May 2019/Published online: 8 August 2019

(C) The Author(s) 2019

\begin{abstract}
Fe-Ni-Te alloys have been experimentally studied using isothermal heat treatments with SEM-EDS and WDS, XRD, and DTA in order to add phase diagram data for a thermodynamic assessment. This is for the application of fission product-induced corrosion of the stainless steel cladding of nuclear fuel pins, where Te is a key element. Phase diagram data are presented at 700 and $800^{\circ} \mathrm{C}$, together with the solidus and liquidus temperatures from 44 to 80 at.\% Te. Metallographic and XRD analysis show that the $\beta 2$ phase forms as a Widmanstätten structure, preferentially precipitated in the $\tau$ phase. SEM images show unidentified precipitates in several samples.
\end{abstract}

Carl-Magnus Arvhult

arvhult@kth.se

Sylvie Poissonnet

Sylvie.POISSONNET@cea.fr

Denis Menut

menut@synchrotron-soleil.fr

Stéphane Gossé

stephane.gosse@cea.fr

Christine Guéneau

christine.gueneau@cea.fr

1 ITM, Department of Materials Science and Engineering, Unit of Structures, KTH Royal Institute of Technology, Brinellvägen 23, 10044 Stockholm, Sweden

2 DEN-Service de Recherches de Métallurgie Physique (SRMP), CEA, Université Paris-Saclay,

91191 Gif-sur-Yvette, France

3 Division Experiences, Ligne MARS, L'Orme des Merisiers, Synchrotron SOLEIL, Saint Aubin, BP 48, 91192 Gif-sur-Yvette, France

4 DEN-Service de Corrosion et du Comportement des Matériaux dans leur Environnement (SCCME), CEA, Université Paris-Saclay, 91191 Gif-sur-Yvette, France
Keywords isothermal equilibration - microstructure · phase diagram - phase transformation - thermal analysis . ternary phase diagram

\section{Introduction}

Tellurium and caesium are key elements in the internal corrosion of the stainless steel cladding of nuclear fuel pins for Generation IV nuclear reactors. In order to model this corrosion, a thermodynamic description of the involved materials is required. To describe the thermodynamics material system, Fe-Ni-Te, thermodynamic and phase diagram data are useful. It is the purpose of this work to contribute to the phase diagram data of the system; already published data are scarce.

\subsection{State of the Art on the Fe-Ni-Te System}

Table 1 presents all known crystallographic data on the Fe$\mathrm{Ni}-\mathrm{Te}$ alloys. This section will briefly discuss the available literature on mainly the ternary alloys; for information on the binaries, the reader is referred to the references.

Stevels briefly covered this alloy system in his thesis ${ }^{[1]}$ about metal tellurides and selenides. A more thorough study was published by Røst and $\AA$ kesson ${ }^{[2]}$ where they proposed the first and only isothermal section on the system, at $600{ }^{\circ} \mathrm{C}$. The $\mathrm{CdI}_{2}$-type $\delta$ phase seems to have full solubility between the $\mathrm{Fe}-\mathrm{Te}$ and $\mathrm{Ni}-\mathrm{Te}$ binary systems. The $\mathrm{Cu}_{2} \mathrm{Sb}$-type $\beta 2$ phase that exists in both $\mathrm{Fe}-\mathrm{Te}$ and $\mathrm{Ni}$-Te have some mutual exchangeability of metal atoms; the phases therefore extend inwards but are interrupted in the center by a ternary $\mathrm{Fe}_{1.5} \mathrm{Ni}_{1.5} \mathrm{Te}_{2}$ phase of rhombohedral structure. Stevels characterized it as extending all the way from $140^{\circ} \mathrm{C}$ to the 
Table 1 Crystallographic data on phases of the Fe-Ni-Te system

\begin{tabular}{|c|c|c|c|c|c|c|c|c|}
\hline \multirow[t]{2}{*}{ Phase } & \multirow[t]{2}{*}{ Pearson symbol } & \multirow[t]{2}{*}{ Space group } & \multicolumn{4}{|c|}{ Lattice parameters, $\AA$} & \multirow[t]{2}{*}{ Prototype } & \multirow[t]{2}{*}{ References } \\
\hline & & & $\mathrm{a}$ & $\mathrm{b}$ & $\mathrm{c}$ & $\beta^{\circ}$ & & \\
\hline FCC & $c F 4$ & $F m \overline{3} m$ & & & & & $\mathrm{Cu}$ & \\
\hline $\mathrm{Fe}-\mathrm{BCC}$ & $c I 2(\mathrm{a})$ & $\operatorname{Im} \overline{3} m$ & & & & & $\mathrm{~W}$ & \\
\hline Te-A8 & $h P 3$ & $P 3_{1} 21$ & & & & & $\gamma$-Se & 10 \\
\hline$\beta 2-\mathrm{Fe}_{1.11} \mathrm{Te}$ & $t P 6$ & $P 4 / n m m: 2$ & 3.82 & $\ldots$ & 6.28 & $\ldots$ & $\mathrm{Cu}_{2} \mathrm{Sb}$ & 11 \\
\hline$\beta 2-\mathrm{Ni}_{3 \pm q} \mathrm{Te}_{2}$ & $t P 6$ & $P 4 / n m m: 2$ & 3.99 & $\ldots$ & 6.09 & $\ldots$ & $\mathrm{Cu}_{2} \mathrm{Sb}$ & 6 \\
\hline$\beta 2-\mathrm{Ni}_{60} \mathrm{Te}_{40}(\mathrm{hn})$ & $m P 8$ & $P 2_{1} / m$ & 7.54 & 3.79 & 6.09 & 91.16 & N/A & 6 \\
\hline$\beta 2-\mathrm{Ni}_{59} \mathrm{Te}_{41}(\mathrm{ln})$ & $o S 10$ & $P m a 2$ & 7.54 & 3.79 & 6.06 & $\ldots$ & N/A & 6 \\
\hline$\beta 1$ (ht) & $\mathrm{cF} 28(\mathrm{a})$ & $F m \overline{3}-/ F \overline{4} 3 m(a)$ & 5.71 & $\ldots$ & $\ldots$ & $\ldots$ & $\beta-\mathrm{Cu}_{2} \mathrm{Se}(\mathrm{a})$ & 1 \\
\hline$\tau-\mathrm{Fe}_{0.28} \mathrm{Ni}_{0.28} \mathrm{Te}_{0.44}$ & $h R 15$ & $R 3 m: h$ & 3.972 & $\ldots$ & 20.34 & $\ldots$ & N/A & 3 \\
\hline$\gamma-\mathrm{FeTe}_{1.183}(\mathrm{ht})$ & N/A & & N/A & & & & N/A & 12 \\
\hline$\gamma 2-\mathrm{NiTe}_{0.85}(\mathrm{ht})$ & N/A & & N/A & & & & N/A & 5 \\
\hline$\gamma 1-\mathrm{Ni}_{52} \mathrm{Te}_{40}$ & $o P 19$ & Pnma & 12.38 & 3.92 & 6.88 & $\cdots$ & $\mathrm{Ni}_{1.10} \mathrm{Se}_{0.16} \mathrm{Te}_{0.74}$ & 13 \\
\hline \multirow[t]{2}{*}{$\delta-(\mathrm{Fe}, \mathrm{Ni})_{2} \mathrm{Te}_{3}$} & $h P 4$ & $P 6_{3} / m m c$ & $3.97-3.87$ & $\cdots$ & $5.36-5.30$ & $\cdots$ & $\mathrm{NiAs}$ & 2,8 \\
\hline & $h P 3$ & $P \overline{3} / m 1$ & $3.80-3.97(b)$ & $\ldots$ & $5.66-5.36(\mathrm{~b})$ & $\ldots$ & $\mathrm{CdI}_{2}$ & 14,15 \\
\hline$\delta-\mathrm{Fe}_{0.75} \mathrm{Te}$ & $m S 14$ & $C 2 / m: b 1$ & 6.702 & 3.856 & 11.228 & 90.65 & N/A & 16 \\
\hline$\epsilon-\mathrm{FeTe}_{2}$ & $o P 6$ & Pnnm & 5.26 & 6.268 & 3.876 & $\ldots$ & $\mathrm{FeS}_{2}$ & 17 \\
\hline
\end{tabular}

$h t$ high temperature; $h n$ low-temperature high nickel; In low-temperature low nickel, (a) Not certain; Stevels compared it to $\mathrm{Cu}_{2} \mathrm{Se}$ due to matching lattice parameter, (b) The different values in the respective binary $\mathrm{Fe}-\mathrm{Te}$ and $\mathrm{Ni}$-Te systems

melting point at $945^{\circ} \mathrm{C}$, but the lower temperature is a superstructure of the higher-temperature phase. Stevels proposed space group $R \overline{3} m$, but found that the calculations did not properly accord with the experimental data. Røst and Àkesson found a rhombohedral ternary phase in their 1972 phase diagram study. ${ }^{[2]}$ Later, Akkesson and Røst ${ }^{[3]}$ made a crystallographic study dedicated to investigating this phase, and they seem to have assumed it to be the same as the one found by Stevels, although they called it $\mathrm{Fe}_{0.28} \mathrm{Ni}_{0.28} \mathrm{Te}_{0.44}$ (which is close to $\mathrm{Fe}_{1.5} \mathrm{Ni}_{1.5} \mathrm{Te}_{2}$ ) and more accurately determined the space group to be $R 3 \mathrm{~m}$.

This rhombohedral phase requires some discussion. Strangely, Røst and Webjørnsen ${ }^{[4]}$ very briefly presented the characterization of a high-temperature rhombohedral phase in the Fe-Te system as being similar to the $R \overline{3} m$ structure proposed by Stevels, ${ }^{[1]}$ without the amendment that Røst made of Ákesson. ${ }^{[3]}$ They concluded that further investigation was in progress, but nothing more was published on this phase. In the 1974 paper, ${ }^{[4]}$ they mention the rhombohedral phase found by Stevels, the one found by Røst and $\AA^{\circ} \operatorname{kesson}^{[2]}$ and the one found by Akesson and Røst, ${ }^{[3]}$ although the latter paper seems to conclude that their rhombohedral phase, also found in their first paper, is the same as the one found by Stevels. ${ }^{[1]}$ Therefore, in this work, we have decided that this might all be the same phase, of the $R 3 m$ space group according to Akesson and Røst, ${ }^{[3]}$ henceforth, called the $\tau$ phase. It might be the case that they are all different superstructures of the same parent phase, similar to the $\beta 2$ phase(s) in Ni-Te, ${ }^{[5,6]}$ but, for the sake of thermodynamic modeling in this application, a distinction between the superstructures is not crucial. In a later paper, ${ }^{[4]}$ it is hypothesized that the rhombohedral phase extends at high temperature all the way to the Fe-Te binary.

Khan and Majumdar ${ }^{[7]}$ performed magnetization studies, and found Curie temperatures of $566-573{ }^{\circ} \mathrm{C}$ for the $\tau$ and the $\delta$ phases, and they state that, in the presence of Te, the Curie temperature does not change much with the variation of the Fe/Ni ratio. Terzieff ${ }^{[8]}$ performed thermal analysis in the $\delta$ phase range (at 61 at.\% Te) and obtained the solidus and liquidus temperatures. Raghavan ${ }^{[9]}$ reviewed the system and redrew the phase diagram of Røst and Åkesson ${ }^{[2]}$ to agree better with the binary data. This phase diagram is reproduced in Fig. 1.

A common property of transition metal tellurides, which seems to be the case for the Fe-Ni-Te alloys, is that they grow in layered structures as $2 \mathrm{D}$ crystals. It is common that they grow in tight layers of Me-Te-Me $(\mathrm{Me}=$ metal) interspaced with more metal sites of very low occupation, and the layers may be held together merely by weak van der Waals bonds.

\section{Experimental Methods}

This section briefly describes the experimental methods used for this work. 
Fig. 1 A digital reproduction of the Fe-Ni-Te isothermal section at $600{ }^{\circ} \mathrm{C}$ from the review by Raghavan, ${ }^{[9]}$ but with updated phase names

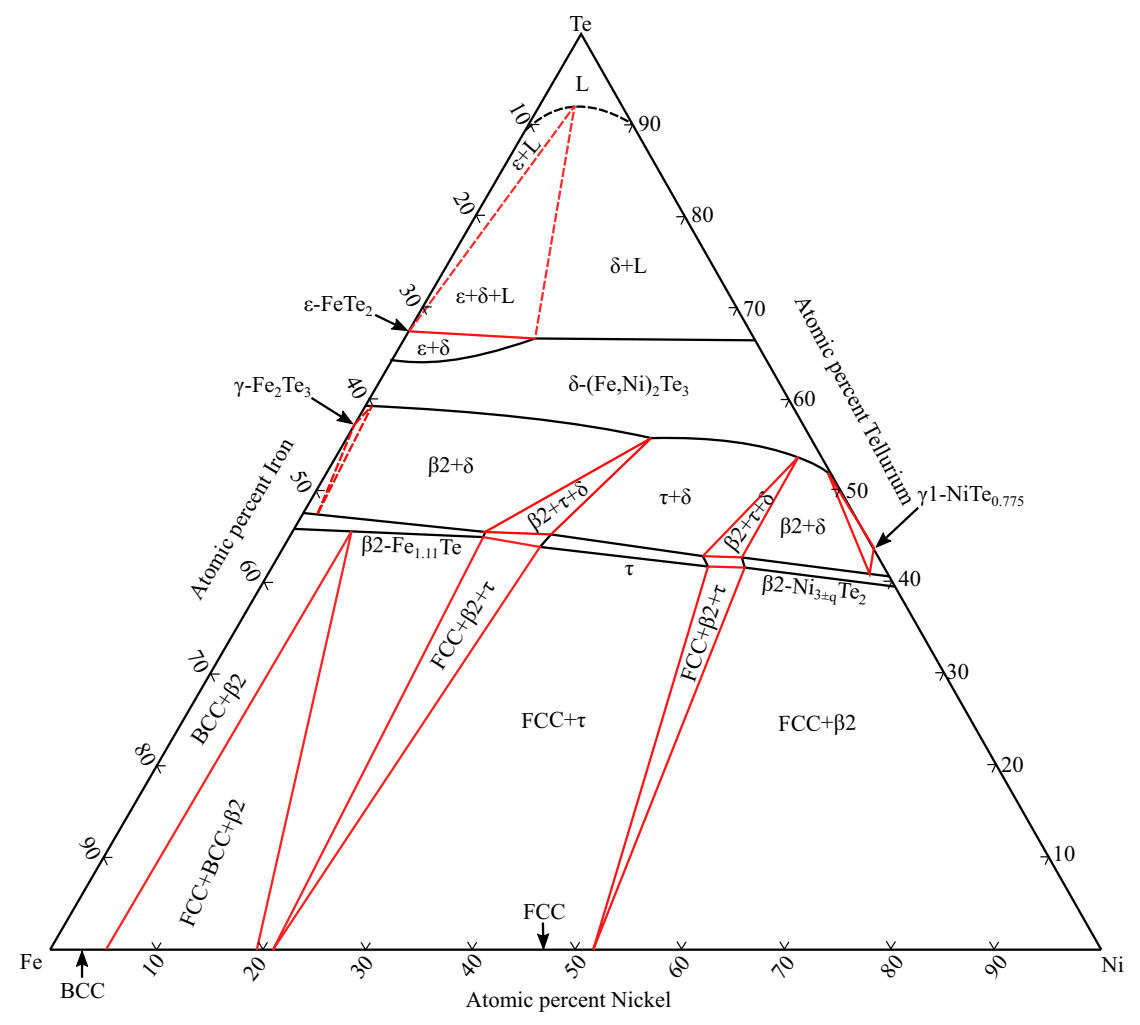

The alloy samples were prepared using $99.9 \%$ pure iron wire from Balzers, > 99.99\% pure nickel rods from SigmaAldrich, and $99.999 \%$ pure nuggets of tellurium from Goodfellow Cambridge, UK. The iron and nickel stocks were polished to remove surface oxides before weighing and collecting them together with tellurium in silica ampoules of two different sizes; large ones with ca 1-g samples for isothermal heat treatments, and small ones with ca 0.1-g samples for differential thermal analysis (DTA). The ampoules were then backfilled with argon and fused sealed. The scale used measured a 0.00005 -g error, resulting in an approximate error of 0.06 at. $\% \mathrm{Fe}, 0.08$ at. $\%$ $\mathrm{Ni}$ and 0.02 at.\% $\mathrm{Te}$ in the prepared compositions for a representative $0.1-\mathrm{g}$ sample, and about 0.006 at.\% Fe, 0.008 at.\% $\mathrm{Ni}$ and 0.002 at.\% Te for the 1-g samples.

During the sample weighing and preparation, all tools and glassware used in the preparation were cleaned in ultrasonic baths with distilled water, then rinsed with ethanol and dried.

\subsection{Isothermal Heat Treatments}

Eleven samples, with compositions shown in Table 2, were prepared in sealed silica tubes and bundled around a thermo-couple, in bundles of 2-4 and inclined in a horizontal tube furnace. The thermo-couple tip was positioned at a level with the samples at the bottom of the tubes. For each bundle, the furnace ran a single program for melting (ca $2 \mathrm{~h}$ ) and slow cooling to isothermal heat treatment of ca $300 \mathrm{~h}$. The samples were never retrieved and powdered, since there was no access to a mill in an inert environment, and performing it in air would risk oxidizing the alloys.

After treatment, while the furnace was still on, the tube was opened and the sample bundle retrieved and dropped into cold water for quenching, with varying efficiency. Here, the samples would have been quenched more efficiently by crushing the ampoules, but this would also risk both oxidizing and breaking the samples, since they were very brittle.

\subsection{Metallographic Analysis}

The samples were retrieved from their ampoules, and coldset in two-component epoxy resin (trials with setting in bakelite for $\mathrm{Fe}-\mathrm{Te}$ alloys crushed the samples ${ }^{[16]}$ ). Thereafter, they were polished with a Struers Tegramin at the lowest possible force $(5 \mathrm{~N})$, with grit 800, 1200 and 2000 $\mathrm{SiC}$ paper, followed by 9,6 and $1 \mu \mathrm{m}$ diamond suspensions. The samples were then rinsed and cleaned, then coated with conductive carbon via electrodeposition, and analyzed first in light optic microscopy (LOM) and then scanning electron microscope (SEM; Zeiss LEO 1450VP). Phase regions were imaged both with secondary electrons (SE) for high resolution, and back-scattered electrons (BSE) giving contrast between regions of different mass. Composition analysis was performed in the SEM energy 
Table 2 Isothermally heat-treated samples with composition data from wavelength dispersive spectroscopy (WDS) and $\mathrm{x}$-ray diffraction $(X R D)$ data

\begin{tabular}{|c|c|c|c|c|c|c|c|c|c|}
\hline \multirow{2}{*}{$\begin{array}{l}\text { Temperature } \\
\text { Sample ID }\end{array}$} & \multirow[t]{2}{*}{$\begin{array}{l}\text { Predicted } \\
\text { region }\end{array}$} & \multicolumn{2}{|c|}{ Prepared composition } & \multicolumn{2}{|c|}{ Boundary composition } & \multicolumn{2}{|c|}{$\begin{array}{c}\text { WDS wt.\% } \\
\text { oxygen }\end{array}$} & \multirow[t]{2}{*}{$\begin{array}{l}\text { Mean sum, } \\
\text { wt.\% }\end{array}$} & \multirow[t]{2}{*}{$\begin{array}{l}\text { Phases found } \\
\text { by XRD }\end{array}$} \\
\hline & & $\begin{array}{l}\text { at. } \% \mathrm{Fe} \\
\pm 0.006\end{array}$ & $\begin{array}{l}\text { at. } \% \mathrm{Ni} \\
\pm 0.008\end{array}$ & $\begin{array}{l}\text { at. } \% \mathrm{Fe}, \mathrm{Ni} \\
\mathrm{SD}=\text { standard }\end{array}$ & $\begin{array}{l}\text { at. } \% \mathrm{Fe}, \mathrm{Ni} \\
\text { deviation }\end{array}$ & Mean & $\operatorname{Max}(a)$ & & \\
\hline \multicolumn{10}{|l|}{$700{ }^{\circ} \mathrm{C}$} \\
\hline FN3711-1 & $\beta 2+\delta$ & 37.15 & 10.82 & $\begin{array}{l}\beta 2: 44.0,10.1 \\
\text { SD: } 0.15,0.11\end{array}$ & $\begin{array}{l}\delta: 31.9,12.22 \\
1.26,0.48\end{array}$ & 0.13 & 1.16 & 103.79 & $\beta 2+\delta$ \\
\hline FN2921 & $\beta 2 / \tau+\delta$ & 28.28 & 21.11 & $\begin{array}{l}\text { Ave: } 35.2,18.5 \\
\text { SD: } 1.47,1.37(b)\end{array}$ & $\begin{array}{l}\delta: 21.5,22.4 \\
0.25,0.34\end{array}$ & 0.15 & 0.67 & 95.65 & $\beta 2+\delta+\tau$ \\
\hline FN2032-1 & $\tau+\delta$ & 19.93 & 32.08 & Tie-line off-center & & 0.24 & 0.92 & 96.31 & Not analyzed \\
\hline FN0647-1 & $\beta 2+\delta$ & 6.00 & 46.93 & $\begin{array}{l}\beta 2: 9.3,49.0 \\
\text { SD: } 0.11,0.22\end{array}$ & $\begin{array}{l}\delta: 2.1,45.1 \\
0.07,0.22\end{array}$ & 0.09 & 0.6 & 104.97 & Destroyed \\
\hline FN2507 & $\operatorname{Liq}+\delta$ & 24.9 & 7.07 & $\begin{array}{l}\text { L: } 17.4,3.0 \\
\text { SD: } 12.6,2.54(b)\end{array}$ & $\begin{array}{l}\delta: 27.9,8.8 \\
0.18,0.14\end{array}$ & 0.02 & 0.19 & 103.1 & $\delta+\mathrm{Te}+\epsilon$ \\
\hline FN1020 & $\operatorname{Liq}+\delta$ & 9.95 & 20.01 & $\begin{array}{l}\text { L: } 8.7,5.9 \\
\text { SD: } 8.83,7.13(b)\end{array}$ & $\begin{array}{l}\delta: 9.9,25.4 \\
0.11,0.15\end{array}$ & 0.07 & 0.23 & 100.90 & $\delta+\mathrm{Te}+\epsilon$ \\
\hline \multicolumn{10}{|l|}{$800^{\circ} \mathrm{C}$} \\
\hline FN3711-2 & $\tau / \beta 2+\delta$ & 36.92 & 11.05 & $\begin{array}{l}\tau: 39.0,13.1 \\
\text { SD: } 2.43,1.41(b)\end{array}$ & $\begin{array}{l}\delta: 32.8,11.5 \\
2.77,0.53(\mathrm{~b})\end{array}$ & 0.10 & 0.66 & 100.40 & Destroyed \\
\hline FN2032-2 & $\tau+\delta$ & 20.06 & 31.91 & $\begin{array}{l}\tau: 25.0,29.2 \\
\text { SD: } 7.88,2.46(b)\end{array}$ & $\begin{array}{l}\delta: 17.3,31.5 \\
0.62,0.33\end{array}$ & 0.14 & 0.53 & 102.31 & Not analyzed \\
\hline FN0647-2 & $\beta 1+\delta(+\gamma 2)$ & 6.02 & 46.99 & $\begin{array}{l}\beta ?: 9.0,48.0 \\
\text { SD: } 0.13,0.22\end{array}$ & $\begin{array}{l}\delta: 4.6,45.3 \\
3.12,1.52(\mathrm{~b})\end{array}$ & 0.15 & 0.25 & 101.87 & $\delta+\beta 2(\mathrm{hn})+?$ \\
\hline FN2713 & $\operatorname{Liq}+\delta$ & 26.95 & 13.00 & Single phase & & 0.03 & 0.72 & 103.19 & $\delta$ \\
\hline FN1220 & $\operatorname{Liq}+\delta$ & 12.02 & 19.96 & $\begin{array}{l}\text { L: } 12.0,16.2 \\
\text { SD: } 6.12,9.33(b)\end{array}$ & $\begin{array}{l}\delta: 8.9,28.4 \\
0.11,0.22\end{array}$ & 0.06 & 0.71 & 101.98 & $\delta+\mathrm{Te}+\epsilon$ \\
\hline
\end{tabular}

Ave Average composition of multiphasic region. E.g., $\beta 2 / \tau$ : Not certain which of the two phases, (a) The point of maximum $\mathrm{O}$ content usually lies on a crack, pore or other surface feature, (b) The standard deviation $(S D)$ means little since the composition of the sample varies greatly due to multiphase region.

dispersive spectroscopy (EDS), and thereafter more accurate composition analysis were made using a microprobe using wavelength dispersive spectroscopy (WDS; Cameca SX50). The WDS analyses focused on quantifying $\mathrm{Fe}, \mathrm{Ni}$, $\mathrm{Te}, \mathrm{O}$ and $\mathrm{Si}$, the latter two due to the observed interaction between the samples and the silica ampoules. Si was rarely found, and the registered $\mathrm{O}$ signals might either be contaminants or fake signals from surface features. When quantifying phase boundaries for the phase diagram, oxygen was ignored by normalizing $\mathrm{Fe}, \mathrm{Ni}$ and $\mathrm{Te}$ contents to only those three elements.

Line scans were made across phase interfaces identified in the BSE imaging. A phase boundary was quantified as the average composition in a phase region, and the phase was deemed as equilibrated when the composition profile in the bulk of a region was flat. The most information would have been obtained if the alloy compositions had been prepared inside three-phase regions, although it is believed that most samples are two-phasic.

\subsection{Differential Thermal Analysis}

A Setaram Setsys 16/18 machine with combined differential thermal analysis and thermogravimetric analysis (DTA-TGA) was used on smaller samples to mainly find the liquidus and solidus temperatures throughout the phase diagram; the TGA was mostly used to see if the ampoules remained intact, where an ampoule breakage would be made apparent by a net mass loss. The sample ampoule was rested in an alumina crucible, opposite to another crucible containing an empty but sealed ampoule. A sample was melted inside the furnace for 30-40 min followed by cooling/heating cycles at rates of 5,3 and $1 \mathrm{~K} / \mathrm{min}$. This was carried out using argon as the carrier and furnace protection gas. The machine was first calibrated to the melting temperatures of pure lead, zinc, silver and gold standards supplied by SETARAM, and a calibration function was fitted, quadratic in temperature and linear in heating rate. Gold was tested in a silica ampoule, which 
resulted in a constant temperature offset of $0.4 \mathrm{~K}$, which was then subtracted from all the measurements on the alloys.

The analysis of phase transitions followed the methodology by Boettinger et al. ${ }^{[18]}$ The onset of a reaction is measured at the first deviation from baseline, and the end of a reaction is measured at the local maximum before return towards baseline. The liquidus temperature can be more accurately obtained at the onset of solidification during cooling than the maximum during heating; this is, however, uncertain since tellurium liquids can be undercooled, and the apparatus was only calibrated for cooling for the last few Fe-Ni-Te samples analyzed. The calibration function on heating gave a mean difference of $0.07 \mathrm{~K}$ when tested on pure elements, while the calibration on cooling gave a mean difference of $1.8 \mathrm{~K}$. With this in mind, the results will be given a conservative estimated error of $\pm 1 \mathrm{~K}$.

\subsection{Synchrotron X-ray Diffraction}

High-energy x-ray diffraction (XRD) was performed on some samples at the MARS beamline of the SOLEIL synchrotron facility, with a wavelength of $0.73 \AA$, in order to verify the present phases. It was presumed that there might be contaminants in terms of small amounts of other phases present than those predicted by composition analysis, in case quenching was not sufficient to prevent some decomposition.

Samples were powdered and placed in capillary tubes before analysis. Three samples were milled by machine, in an attempt to obtain a somewhat uniform particle size, after experience with Fe-Te alloys resulting in extremely textured samples. ${ }^{[16]}$ After the first analyses, it was realized that this probably destroyed the weak van der Waals interlayer bonds of the telluride crystals, and the remaining samples were mortared by hand instead.

\section{Results and Discussion}

\subsection{Isothermally Heat Treated Samples}

A summary of the isothermally heat treated samples are presented in Table 2. The isothermally heat-treated samples are named FNXXYY, where FN stands for $\mathrm{Fe} \mathrm{Ni}$, and where $\mathrm{XX}$ is the approximate atomic percent of Fe and YY the approximate atomic percent of $\mathrm{Ni}$ in the sample. In the two following subsections, the samples will be discussed in the order of increasing Te-content, from Fe-rich to Ni-rich. The results are summarized in Table 2. If a sample ID is indexed 1 or 2 , it means that the same composition was treated at both two isotherms, and 1 then means $700{ }^{\circ} \mathrm{C}$ and
2 means $800{ }^{\circ} \mathrm{C}$. In Table 2 , the equilibrium composition of stable phases are given with their standard deviation where applicable, but It is not applicable, e.g., if the composition of the liquid was evaluated by measuring the average composition of the area that used to be liquid, and now contains multiple phases of greatly varying composition; in that case, the standard deviation would not mean much.

\subsubsection{Samples at $700{ }^{\circ} \mathrm{C}$}

Sample FN0647-1 contained large dendritic primary precipitates, seemingly eutectic, surrounded by a mass of high-Te phase with an eutectic microstructure of smaller precipitates of the same composition as the dendrites. The composition of the high-Te phase fits the $\delta$ phase and the dendrites fit the $\beta 2$ phase. This sample was powdered by machine-milling, and the high-energy XRD only showed signs of amorphous material; it is possible that the milling broke the weak inter-layer bonds of the crystals.

FN2032-1 was troublesome to prepare, and there was extensive surface damage although the polishing procedure was repeated three times. It was hoped that this sample would be composed of $\tau+\delta$, but composition analysis seems inconclusive. There are large oblong precipitates, surrounded by a seemingly eutectic structure. The sum of wt.\% measured in WDS were on average 96, and at its lowest 84 , indicating that some element is missing from the analysis, the surface is not sufficiently flat. This sample had the highest oxygen contamination. Small composition gradients near the edge of the large precipitates indicate that diffusion might have occurred during quenching. The sample was not analyzed via XRD since it was contaminated, and not in equilibrium.

Sample FN2921 was prepared to figure out what happened to FN2032, and is by composition located between that and FN3711 in the phase diagram. Sample FN2921, as seen in the SEM BSE image of Fig. 2, contains white regions with parallel dark precipitates, as we have already believed to be $\delta$ phase, and a dark region. Clearly visible even in LOM, the dark region contains a secondary precipitate of what looks like a Widmanstätten structure, characterized by parallel sheets growing in 3 distinct directions at $60^{\circ}$ angle to each other. The typical structure is commonly formed in meteorites, cooling slowly in space, w. The structure is rather coarse, implying it did not form when quenching but during slow cooling or during the isothermal heat treatments. The entire dark region has a uniform Te-content, but the Widmanstätten precipitates are richer in $\mathrm{Fe}$ and the surrounding mass richer in $\mathrm{Ni}$. It is possible that there is a three-phase region here at $700{ }^{\circ} \mathrm{C}$, with Widmanstätten $\beta 2$ selectively precipitating in the $\tau$ phase. This might imply that, during cooling, when the $\beta 2$ 
Fig. 2 SEM image of sample FN2921 showing the interface between the white region $(\delta$ phase) and the dark region $(\beta 2+\tau)$

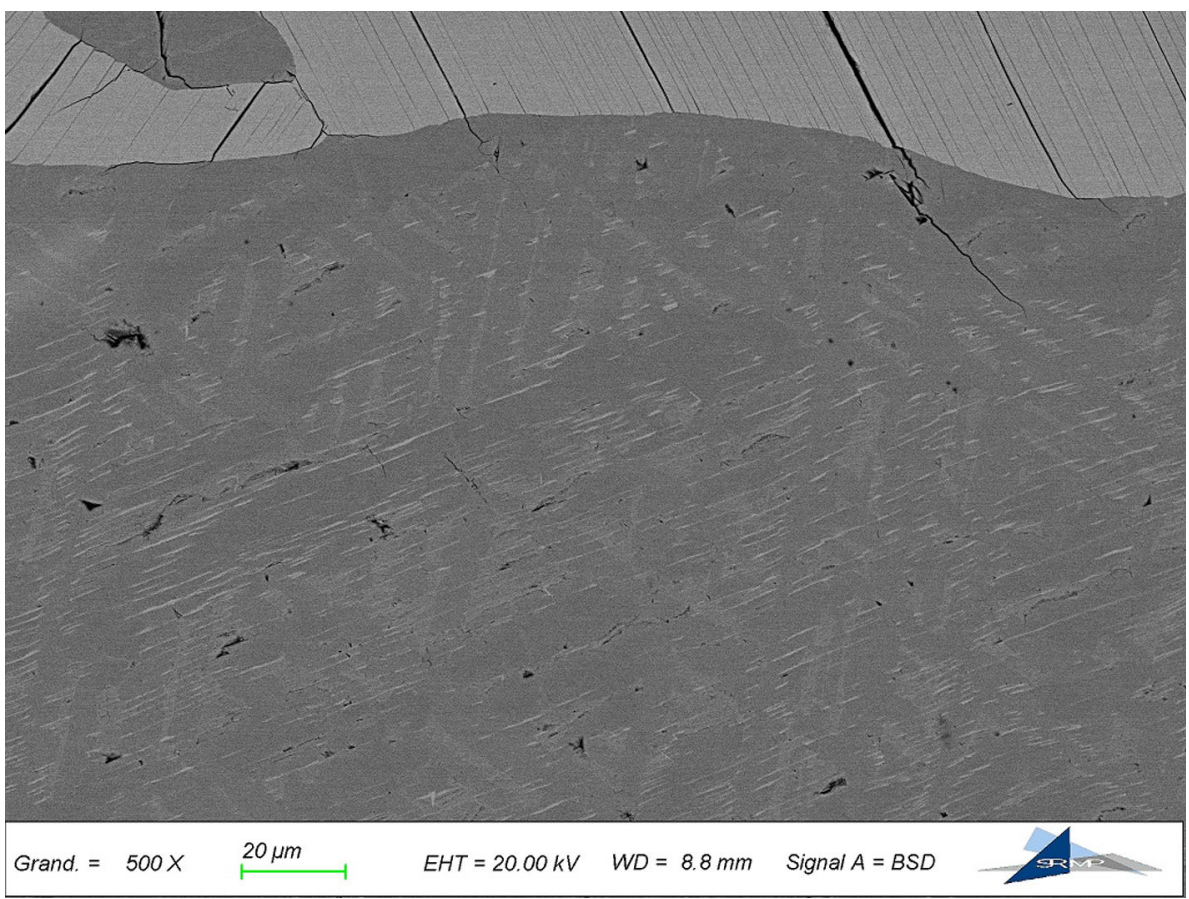

phase began forming there was already a significant amount of the $\tau$ phase present, implying that it is indeed possible that $\tau$ extends above the $\beta 2$ phase at higher temperature. White parallel streaks can be seen in Fig. 2. One could believe that they were scratches from polishing, but, upon magnifying (Fig. 9), it is clear that they are a Te-rich precipitates which grow in a preferred direction. It seems reasonable that they were formed on cooling during retrieval. A composition analysis could not be made with the given metallographic techniques. Numerical fitting of the XRD powder pattern of FN2921 confirms the presence of $\delta, \beta 2$ and small amounts of the $\tau$ phase.

FN3711-1 contained large rectangular precipitates of low-Te phase consistent with $\beta 2$, surrounded by a white region of higher Te-content consistent with the $\delta$ phase (see Fig. 3). On zooming in, as seen in Fig. 3, parallel dark stripes appear in the $\delta$ regions. They were hard to analyze in WDS since they are the same thickness as the affected region, on the order of $\mu \mathrm{m}$, but they seem to contain less Te and more Fe than the white mass. Perhaps, it is a superstructure of the $\delta$ phase. Therefore, a rectangular grid of about 100 points was measured, and the average composition was taken in the white region in order to evaluate the equilibrium $\delta$ phase composition. XRD confirmed that the sample was composed of the $\beta 2$ and $\delta$ phases; no other peaks were found strong enough to characterize the stripes.

FN1020 and FN2507 were partially liquid with large primary $\delta$ precipitates surrounded by peritectic dendrites interspersed with almost pure Te. Grid scans were made over the dendrites in order to obtain the composition of the liquid before final solidification, and XRD confirmed the presence of $\delta$, pure Te and $\epsilon$-FeTe $e_{2}$. There is probably a large multiphase region involving the $\epsilon$ phase at lower temperatures.

\subsubsection{Samples at $800{ }^{\circ} \mathrm{C}$}

Sample FN0647-2 was predicted to contain the $\beta 1$ and $\delta$ phases, and maybe some of the stoichiometric Ni-Te $\gamma^{2}$ phase if the 3-phase region extends to such high Fe-content. The sample was found to contain dendritic primary precipitates of low Te-content surrounded by a mass of high-Te phase, with smaller precipitates in the surrounding phase. XRD fits the $\delta$ phase, and $\mathrm{NiAs}$ and $\mathrm{CdI}_{2}$ types equally well, and the orthorhombic low-Ni superstructure of the $\beta 2$ phase. It seems that $\beta 1$ phase has formed followed by an eutectic solidification, with perhaps some secondary precipitation when $\beta 1$ decomposed into the $\beta 2$ phase. Inside the dark dendritic phase, one finds peculiar sheets of higher Te-content that have grown in pseudorectangles (see Fig. 10). They seem to have lower Fecontent, of only 5 at.\%. One could believe that this could be the $\gamma 1$ phase, with a small amount of Ni replaced by Fe, that has a crystal structure similar to the orthorhombic $\beta 2$ phase, which would explain the preference of precipitation in dark regions; but there are two extra peaks in the XRD pattern that do not fit the $\gamma 1$ phase. For composition analysis, the flat composition profile of the dark dendrites were taken as the $\beta 1$ or $\beta 2$ phase boundary, and a grid average was made on the eutectic region for the $\delta$ phase boundary.

Sample FN2032-2 was predicted to lie in a $\tau+\delta$ region, and contains large dark oblong precipitates surrounded by a 
Fig. 3 SE image of sample FN3711-1 with BSE image overlain, showing white regions ( $\delta$ phase) and dark regions $(\beta 2$ phase). Superimposed LOM image is zoomed-in on stripes in the $\delta$ regions

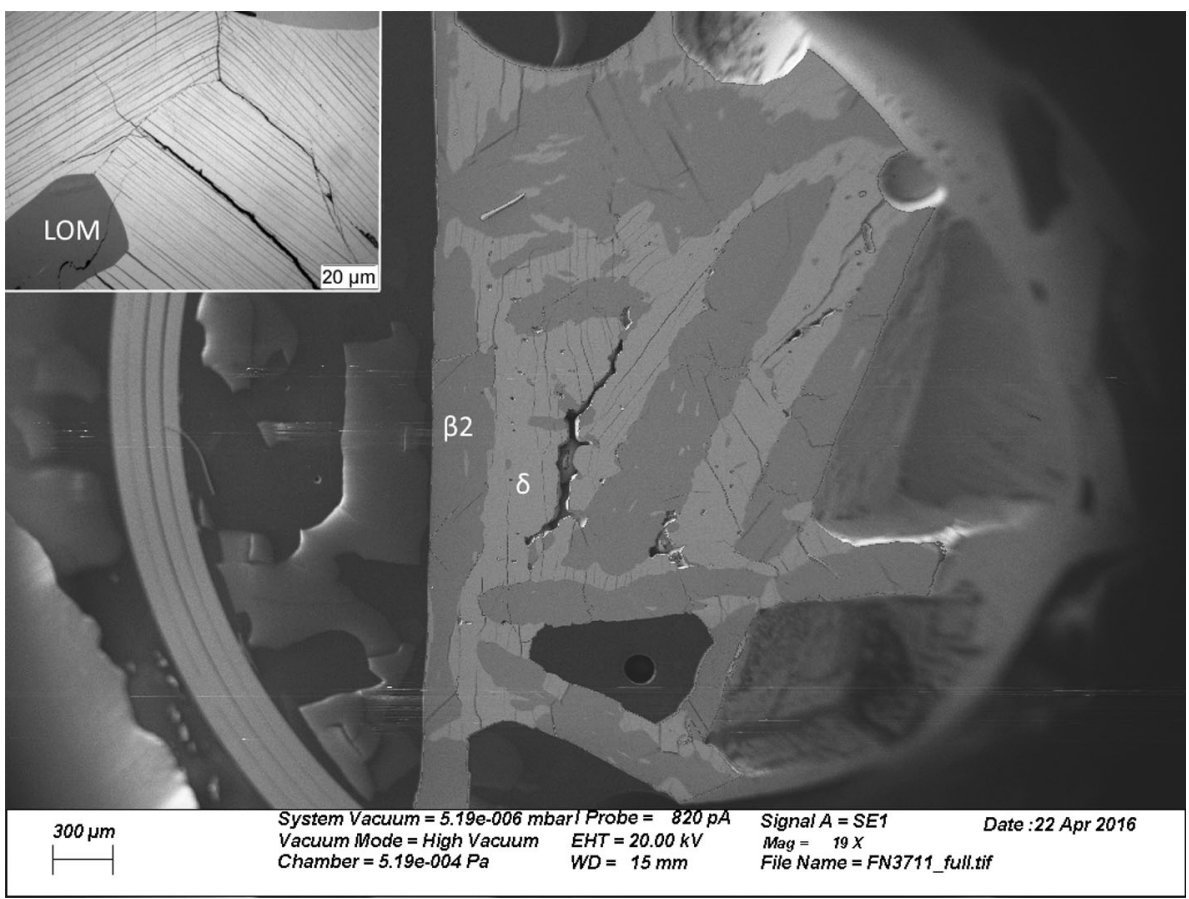

white, high-Te mass speckled with smaller dark precipitates. The flat composition of the white phase has an unreasonably high Te-content compared to FN0647 and the binary Ni-Te $\delta$ phase, so it seemed proper to make a grid average in the white regions with small dark precipitates. The large dark precipitates contain very thin, parallel sheet precipitates of darker contrast in LOM (Fig. 11), which were not apparent in BSE imaging. Perhaps, they were formed on quenching, so a grid average was performed there as well. The composition seems consistent with a possible $\tau$ phase, and the tie-line is only slightly offset from the average alloy composition. Perhaps, the thin sheets are a low-temperature allotrope of the $\tau$ phase discussed before.

FN3711-2 BSE images show yet again large dark precipitates in a surrounding white mass of high-Te phase containing dark parallel stripes. Like sample FN2921, the dark precipitates contain thin, white, parallel streaks of another precipitate. Grid averages were made with WDS to evaluate the equilibrium phase boundaries. A small separate piece of the sample was analyzed separately, and it contained almost no $\mathrm{Ni}(1.5$ at.\%) and has a composition consistent with the Fe-Te $\delta$ phase, showing the elusive zigzag microstructure found in the literature. ${ }^{[16]}$ This time, however, the structure was coarse enough to quantify, and it appears to be close to the composition of the supposedly stoichiometric Fe-Te $\gamma$ phase (54.2 at.\% Te) with a minimum of 53.86 at.\% Te on the zig-zags. This sample was also machine-milled, and therefore XRD showed no crystalline phase.
FN1220 and FN2713 were prepared to be in the $\delta+\mathrm{L}$ region. FN1220 indeed showed peritectic precipitates surrounded by a mass of mostly Te, and XRD confirmed the presence of the $\delta$ phase of the $\mathrm{CdI}_{2}$ type, pure Te and even some $\epsilon-\mathrm{FeTe}_{2}$. FN2713 showed no solidification structures; however, the sample was partitioned after retrieval into many small drop-like pieces. This sample showed the most interaction between the alloy and the ampoule. As can be seen in Fig. 12, micro- and nano-beads were found at the interface between the alloy and silica. EDS line scans revealed that next to the $\mathrm{SiO}_{2}$ is a layer of $\mathrm{Si}_{2} \mathrm{Te}_{3}$, with the beads being a mix of mainly $\mathrm{Si} / \mathrm{Te} / \mathrm{O}$ with some $\mathrm{Fe}$ and $\mathrm{Ni}$. One piece of FN2713 was analyzed with WDS, showing what seemed to be a single phase of $\delta$ composition. The XRD pattern confirmed a predominance of the $\delta$ phase with an indication of an amorphous "hill" and a few small extra peaks. It is possible that most of what was liquid was consumed in the reaction with the silica.

\subsection{DTA results}

The DTA data are most easily presented in Fig. 4, showing the melting temperature for all of the analyzed compositions, in isoplethal sets of different constant Te-content. The dataset by Terzieff $\mathrm{f}^{[8]}$ is also included for comparison, and it is seen that the melting temperatures steadily falls from the metal-rich side (44 at.\% Te) towards the Te corner. It is apparent in the diagram that the liquidus at high-Ni content increases again to 61 at.\% Te before falling steeply, indicating that the congruent melting of the $\delta$ phase in Ni-Te 


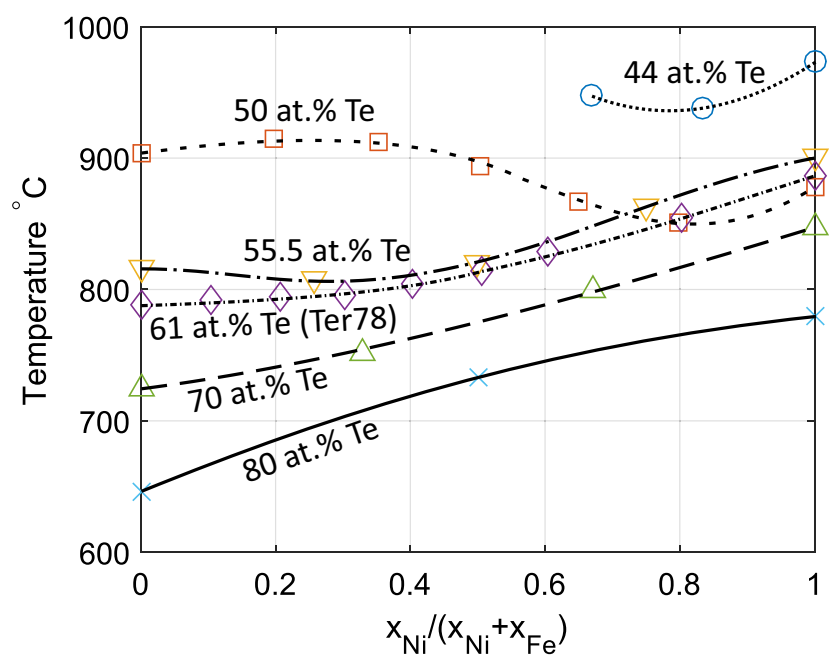

Fig. 4 Isoplethal liquidus data in the Fe-Ni-Te system for varying Tecontent evaluated in this work, with rough lines connecting the points. Data of 61 at.\% Te from Terzieff. ${ }^{[8]}$ Binary data from Arvhult et al. ${ }^{[19,20]}$

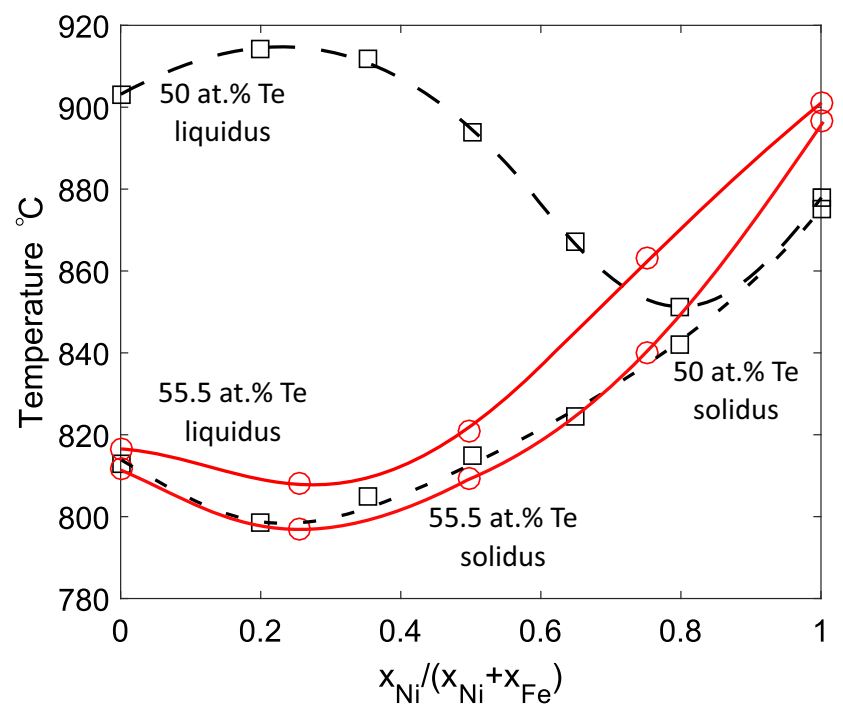

Fig. 5 Isoplethal liquidus and solidus data with tentative curvature, showing the melting interval of Fe-Ni-Te alloys for 50 at.\% and 55.5 at. $\%$ Te. Binary data from Arvhult et al. ${ }^{[19,20]}$

(close to 55.5 at. $\% \mathrm{Te}^{[5]}$ ) extends a little into ternary compositions. The solidification temperatures are also plotted for 50 at. $\%$ and 55 at. $\%$ Te in Fig. 5. At 50 at.\% Te, there is an eutectic reaction in $\mathrm{Ni}-\mathrm{Te},{ }^{[5]}$ and it seems by the proximity of the liquidus and solidus that there is an eutectic valley going in the direction of added Fe. All solidus and liquidus temperatures are given in Table 3. As can be seen in the table, the samples at 70 and 80 at.\% Te have the same solidus temperature $(445 \mathrm{~K})$; this is probably an invariant 4 -phase eutectic of Liquid $\leftrightarrow \mathrm{Te}-\mathrm{A} 8+\delta+\epsilon-\mathrm{FeTe}_{2}$.

One composition in particular was problematic: that of sample FN3311 (Table 3). During the first experiment, a 22\% mass loss was recorded, and the ampoule was cracked during cooling. A new sample was prepared of the same composition, and this time the ampoule was cleft open during heating, $2 / 3$ of the sample had vaporized and the thermo-couples were shattered, having been exposed to tellurium. Strangely, the leak occurred during heating, before the sample was liquefied. Since both experiments at this composition consistently broke, there might be a phase transformation and a resulting volume expansion that facilitated the breakage.

\subsection{Phase Diagrams of the Fe-Ni-Te System}

Figures 6 and 7 show isothermal phase diagram sections at 700 and $800{ }^{\circ} \mathrm{C}$, respectively, including the as-prepared compositions of the samples for isothermal heat treatments, and tie-lines drawn between the selected phase boundary compositions from the WDS analyses. The Thermo-Calc software package was used to plot the blank triangular diagram and experimental data points; ${ }^{[21]}$ overlaid in the diagram are hand-drawn tentative phase boundaries based on the results. In cases where what seemed to have been a single phase region containing several microstructures with different BSE contrast, a large grid of composition measurements was made and the average used. In such a case, one has either happened to obtain a three-phase sample with one phase being crystallographically similar to another, so that it preferentially precipitates in only one region, or there has been a decomposition on cooling. For the liquidus data points, areas with peritectic dendrites were easily identified and a grid average was taken. Tielines have been drawn for samples where we believe homogenized two-phase equilibria were achieved, and most of them seem to pass through the average sample compositions (solid fill) which indicates both the prepared compositions being relatively accurate.

\section{Conclusions and Future Work}

The present work has presented experimental tie-lines in two-phase regions of the $\mathrm{Fe}-\mathrm{Ni}-\mathrm{Te}$ system at 700 and $800{ }^{\circ} \mathrm{C}$ for samples with Te-contents of $47-70$ at. $\% \mathrm{Te}$, in order to complement the sole isothermal section available in the literature for $600{ }^{\circ} \mathrm{C}$. XRD results back up most predictions of phases present in the samples. In addition, 


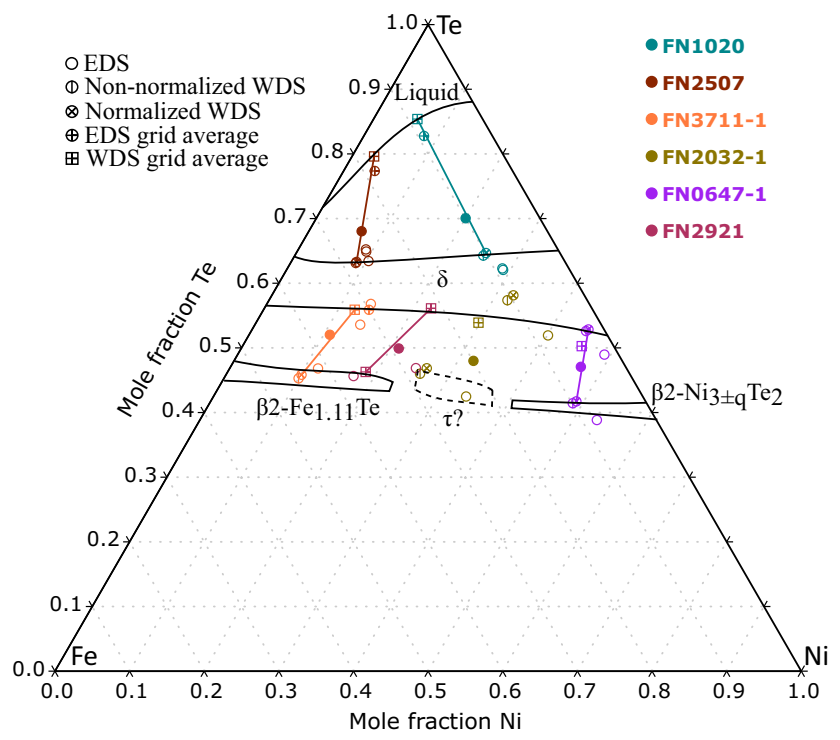

Fig. 6 Isothermal section of $\mathrm{Fe}-\mathrm{Ni}-\mathrm{Te}$ system at $700^{\circ} \mathrm{C}$ with handdrawn hypothesized phase boundaries, and experimental data points from isothermal heat treatments with tie-lines

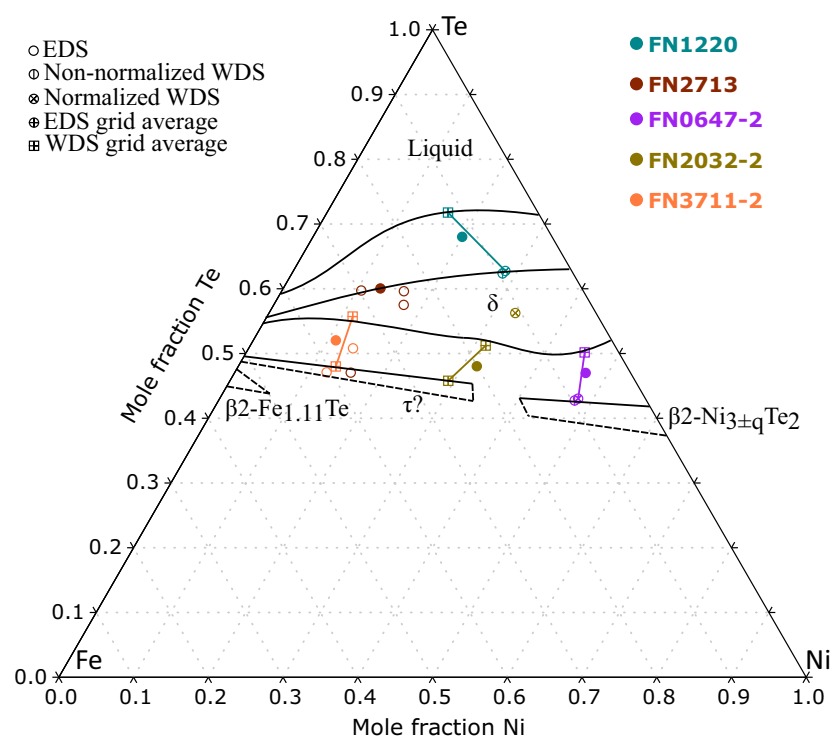

Fig. 7 Isothermal section of $\mathrm{Fe}-\mathrm{Ni}-\mathrm{Te}$ system at $800^{\circ} \mathrm{C}$ with handdrawn hypothesized phase boundaries, and experimental data points from isothermal heat treatments with tie-lines

DTA studies present the liquidus and solidus temperatures for isoplethal sections of $44-80$ at.\% Te, complementing the work by Terzieff, ${ }^{[8]}$ which only considered 61 at.\% Te. Metallographic studies show that the $\beta 2$ phase forms Widmanstätten structures, precipitated inside the ternary $\tau$ phase regions, which supports theories that the $\tau$ phase extends at higher temperature to reach above the $\beta 2$ phase towards the Fe-Te binary high-temperature rhombohedral phase, ${ }^{[2]}$ also known as $\beta^{\prime} .^{[22]}$ Alloys with a composition of 33 at.\% $\mathrm{Fe}$ and 11 at.\% Ni seem to experience a phase transition at high temperature resulting in an expansion in volume, breaching the sample containment. Samples with more than half of the metal atoms being $\mathrm{Fe}$, and on the lowTe side of the $\delta$ phase, show perfectly parallel $\mu \mathrm{m}$-thin sheet precipitates in $\delta$ phase regions, with lower Te- and higher Fe-content. It is still not certain what phase these are, but it is probable that they are either a superstructure of the $\delta$ phase(s) or another, perhaps stoichiometric, phase of similar structure.

It might be of interest for future work to investigate the nature of the strange 2D precipitates found throughout this work, e.g., the white precipitates in samples of 6 at.\% Fe and 47 at. $\% \mathrm{Ni}$, and the dark stripes in the $\delta$ phase in samples of 37 at.\% $\mathrm{Fe}$ and 11 at.\% $\mathrm{Ni}$, as well as 29 at.\% $\mathrm{Fe}$ and at.\% Ni.

This work was performed in order to gather more phase diagram data for a thermodynamic assessment of the Fe$\mathrm{Ni}-\mathrm{Te}$ system, which is currently in progress.

Acknowledgments Open access funding provided by Royal Institute of Technology. The main author, C.-M.A., is grateful to the Swedish Research Council (Vetenskapsrådet) for the funding of the $\mathrm{PhD}$ project, which is part of the SAFARI project of the CEA-SRC collaboration for R\&D of the ASTRID generation IV reactor. Furthermore, C.-M.A. is grateful to all the colleagues at CEA providing resources and guidance in all experimental methods: Sylvie Chatain for teaching him how to calibrate and use the DTA apparatus, Kevin Ginestar for teaching how to prepare samples and use the SEM, Christophe Bonnet for aiding with sample preparation for XRD analysis, and Bonnie Lindahl for performing some of those XRD analyses. He also thanks his colleagues at CEA and KTH for all the advice provided for the analysis of microstructures. The authors are grateful to Patrick Bonaillie at DEN-SRMP, Université Paris-Saclay, for carring out the SEM imaging and EDS analysis on some of the samples. Last of all, C.-M.A. wishes to thank Prof. Malin Selleby for the supervision throughout his Ph.D. work.

Conflict of interest The authors of the present work declare no conflict of interest.

Open Access This article is distributed under the terms of the Creative Commons Attribution 4.0 International License (http://crea tivecommons.org/licenses/by/4.0/), which permits unrestricted use, distribution, and reproduction in any medium, provided you give appropriate credit to the original author(s) and the source, provide a link to the Creative Commons license, and indicate if changes were made.

\section{Appendix: Images and Tables}

See Fig. 8, 9, 10, 11 and 12 and Table 3. 
Fig. 8 SEM EDS element

mapping of a section of the dark regions in FN2921. Oxygen was found in trace amounts

uniformly distributed
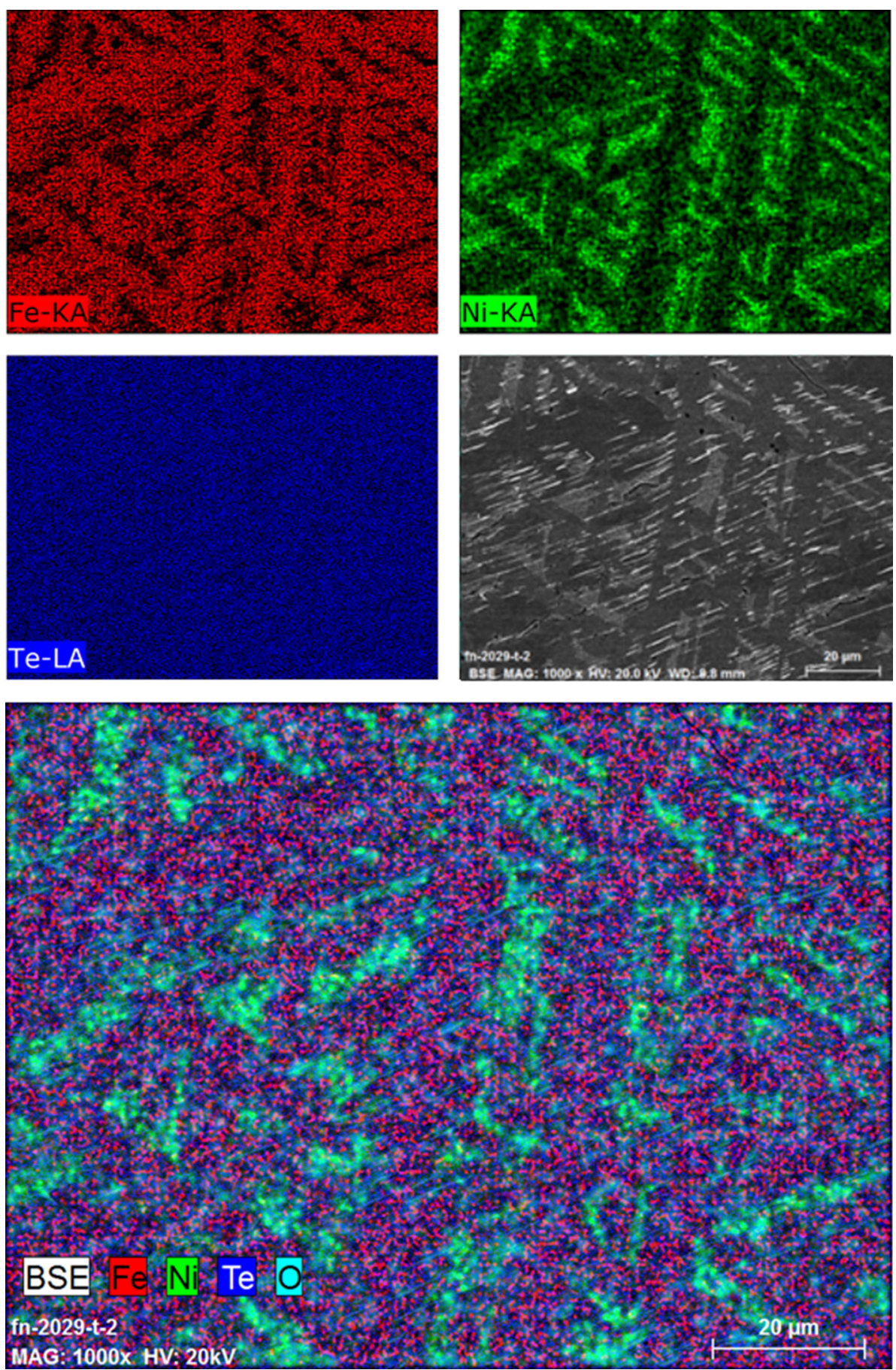
Fig. 9 SEM BSE image of $\beta 2+\tau$ region in FN2921, magnified on white streaks

Fig. 10 SEM BSE image of dendritic primary precipitates in FN0647-2, zoomed in on white precipitates in the dendrites
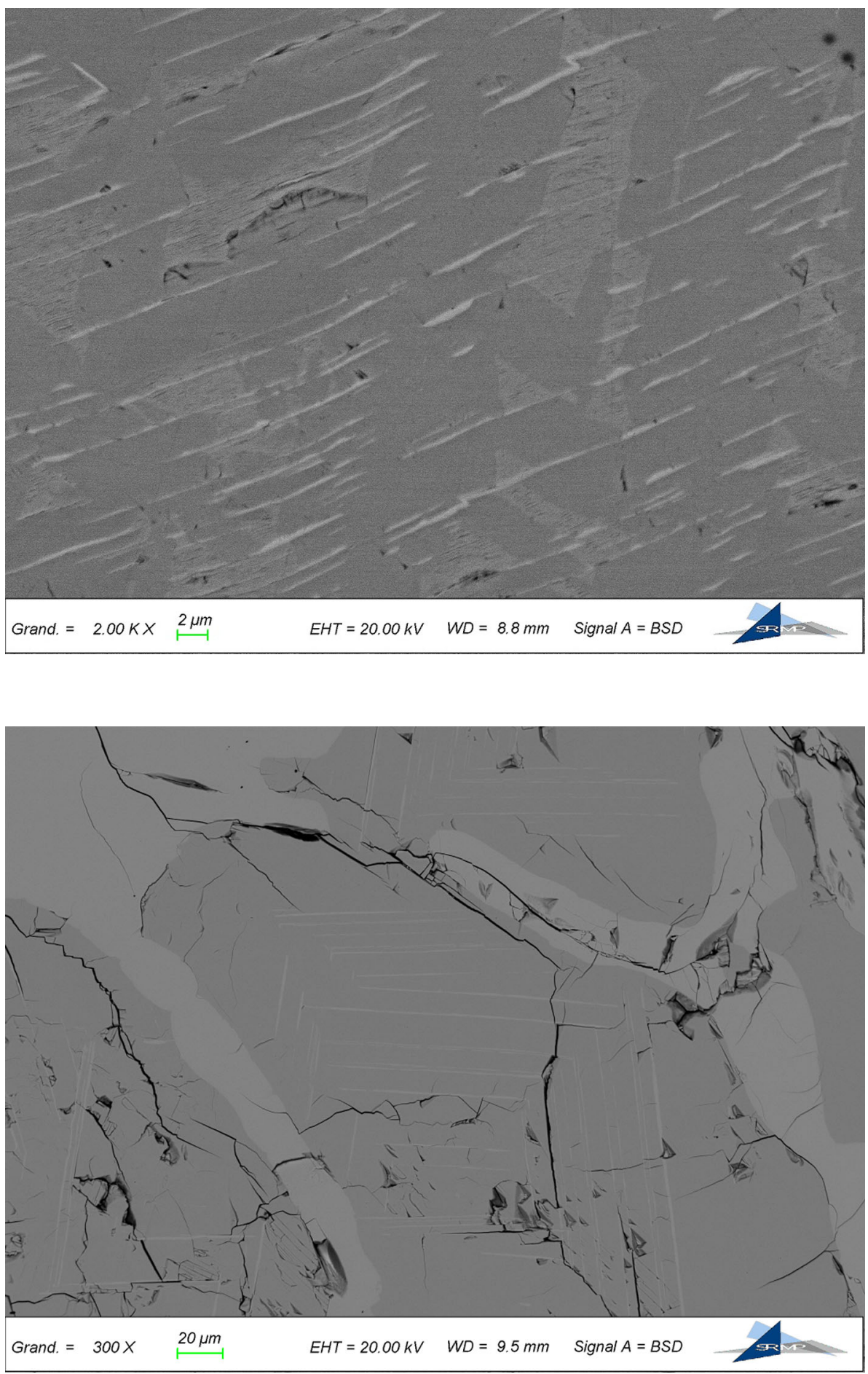


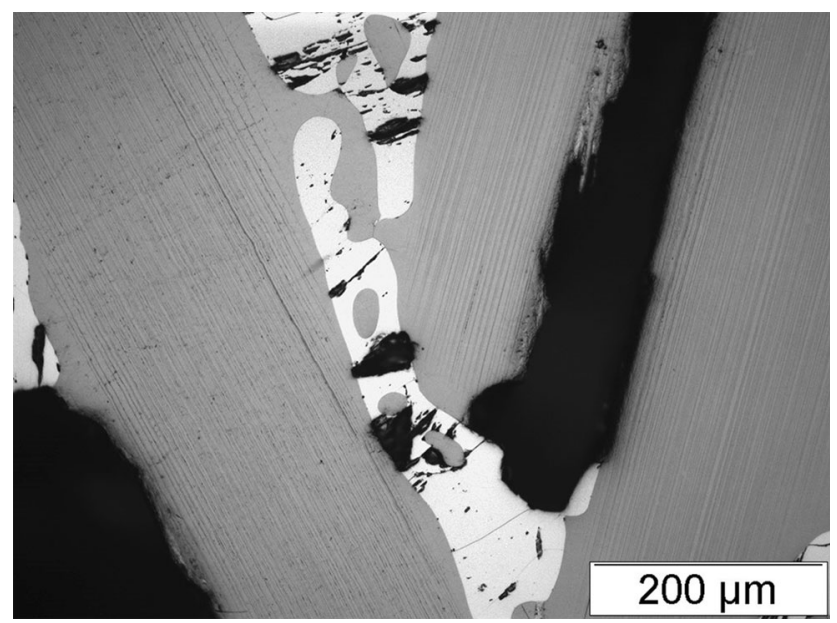

Fig. 11 LOM image at $20 \times$ magnification of large precipitates in FN2032, showing dark parallel precipitates therein
Table 3 Liquidus and solidus temperatures of Fe-Ni-Te alloys, sorted in groups of increasing Te-content

\begin{tabular}{rrrll}
\hline Sample ID & \multicolumn{2}{c}{ Composition } & Liquidus & Solidus \\
\cline { 2 - 3 } & $\begin{array}{c}\text { at.\% Fe } \\
\pm 0.06\end{array}$ & $\begin{array}{c}\text { at.\%Ni } \\
\pm 0.08\end{array}$ & $\pm 1{ }^{\circ} \mathrm{C}$ & $\pm 1{ }^{\circ} \mathrm{C}$ \\
\hline 44 at.\% Te & & & & \\
FN0947 & 9.26 & 46.78 & 938.5 & 848.4 \\
FN1937 & 18.66 & 37.44 & 947.8 & 862.6 \\
50 at.\% Te & & & & \\
FN1040 & 10.03 & 39.88 & 851.0 & 842.0 \\
FN1733 & 17.48 & 32.59 & 867.1 & 824.7 \\
FN2525 & 24.90 & 25.23 & 893.8 & 814.7 \\
FN3317 & 32.34 & 17.61 & 911.8 & 804.8 \\
FN4010 & 40.22 & 9.94 & 914.3 & 798.5 \\
55.5 at.\% Te & & & & \\
FN3311 & 33.20 & 11.44 & $808.1(\mathrm{a})$ & $797.0(\mathrm{a})$ \\
FN2222 & 22.28 & 22.17 & 820.7 & 809.2 \\
FN1133 & 11.08 & 33.39 & 863.2 & 839.9 \\
70 at.\% Te & & & & \\
FN2010 & 20.32 & 9.94 & 751.6 & 445.1 \\
FN1020 & 10.01 & 20.46 & 799.0 & 444.1 \\
80 at.\% Te & & & & 445.4 \\
FN1010 & 9.96 & 9.97 & 733.1 & \\
\hline
\end{tabular}

(a) Sample broke and mass was lost; however, there were sufficient data to evaluate liquidus and solidus
Fig. 12 SEM BSE images of the inside of the silica ampoule of sample FN2713, with a zoomed-out image overlayed
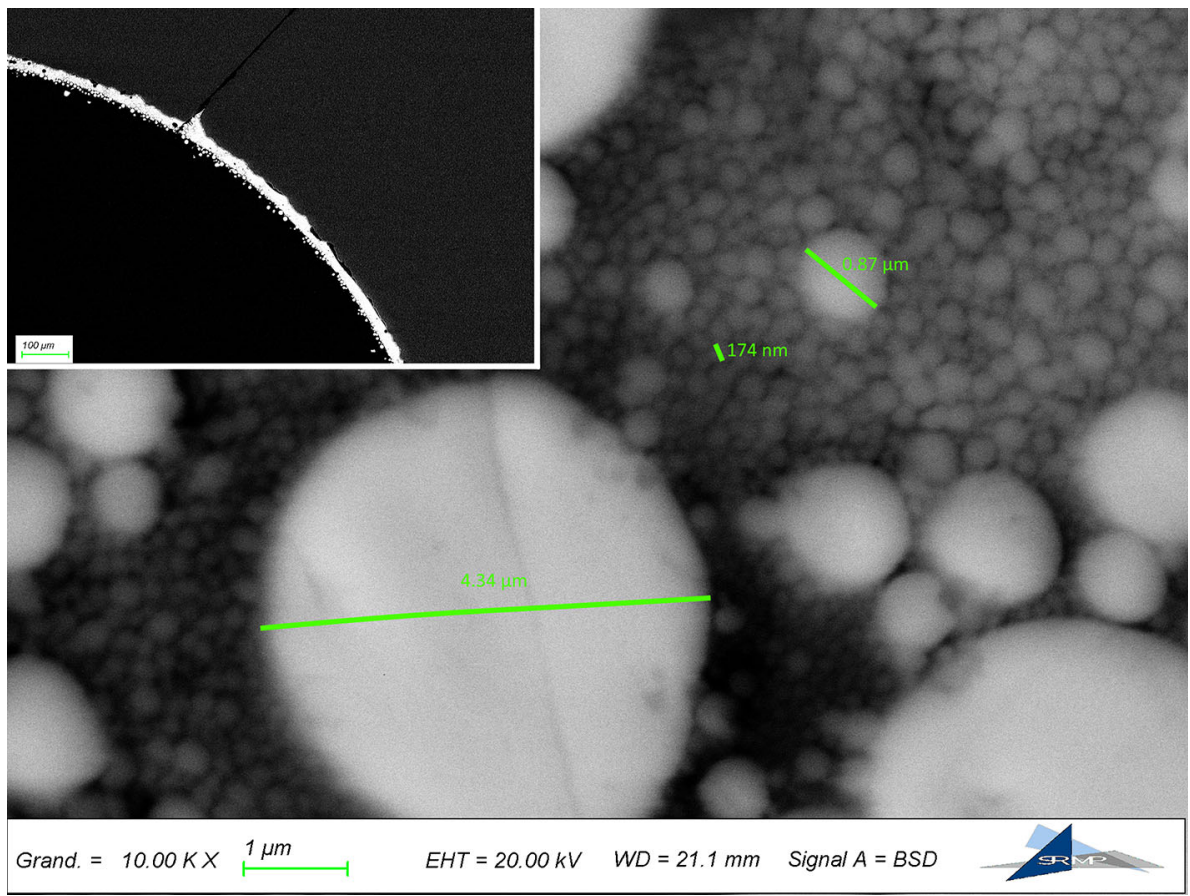


\section{References}

1. A.L.N. Stevelsm, Phase Transitions in Nickel and Copper Selenides and Tellurides, $\mathrm{PhD}$ thesis, University of Groningen, 1969

2. E. Røst, G. Åkesson, J. Krogh-Moe, J. Songstad, and A. Pilotti, On the System Fe-Ni-Te, Acta Chem. Scand., 1972, 26, p 36623670. https://doi.org/10.3891/acta.chem.scand.26-3662

3. G. Åkesson and E. Røst, The Crystal Structure of Fe0.28Ni0.28Te0.44, Acta Chem. Scand., 1973, 27, p 79-84. https://doi.org/10.3891/acta.chem.scand.27-0079

4. E. Røst and S. Webjørnsen, A High Temperature Iron Telluride with Rhombohedral Structure, Acta Chem. Scand. A, 1974, 28(3), p 361-362

5. K.O. Klepp and K.L. Komarek, Übergangsmetall-Chalkogensysteme, 3. Mitt.: Das System Nickel-Tellur, Mon. Chem. Chem. Mont. Chem., 1972, 103, p 934-946

6. L.D. Gulay and I.D. Olekseyuk, Crystal Structures of the Compounds $\mathrm{Ni3Te} 2, \mathrm{Ni} 3-\delta \mathrm{Te} 2(\delta=0.12)$ and $\mathrm{Ni1} .29 \mathrm{Te}, J$. Alloys Compd., 2004, 376(1-2), p 131-138. https://doi.org/10.1016/j. jallcom.2003.12.022

7. D.C. Khan and A.K. Majumdar, Magnetization Studies of Fe-NiTe Alloys, Physica, 1978, 95B, p 211-214. https://doi.org/10. 1016/0378-4363(78)90094-3

8. P. Terzieff, Magnetische Messungen an Ternären Fe/Ni-Telluriden Mit NiAs-Struktur, Mon. Chem., 1978, 109(3), p 567-573. https://doi.org/10.1007/BF00912774

9. V. Raghavan, The Fe-Ni-Te (Iron-Nickel-Tellurium) System, Chap 261, in Phase Diagrams of Ternary Iron Alloys, Indian Institute of Metals, 1992, p 1081-1085

10. C. Adenis, V. Langer, and O. Lindqvist, Reinvestigation of the Structure of Tellurium, Acta Crystallogr., 1989, 45(6), p 941-942. https://doi.org/10.1107/S0108270188014453

11. J. Leciejewicz, O. Samuelson, A. Holm, P.H. Nielsen, and J. Munch-Petersen, A Neutron Diffraction Study of Magnetic Ordering in Iron Telluride, Acta Chem. Scand., 1963, 17, p 25932599. https://doi.org/10.3891/acta.chem.scand.17-2593

12. F. Grønvold, H. Haraldsen, and J. Vihovde, Phase and Structural Relations in the System Iron Tellurium, Acta Chem. Scand., 1954, 8, p 1927-1942

13. L.D. Gulay, M. Daszkiewicz, and A. Pietraszko, Evidence of a Centre of Symmetry: Redetermination of Ni2.60Te2 from Single-
Crystal Data, Acta Crystallogr. Sect. E Struct. Rep. Online, 2007, 63(11), p i188. https://doi.org/10.1107/S1600536807050568

14. J.B. Ward and V.H. Mccann, On the $57 \mathrm{Fe}$ Mossbauer Spectra of FeTe and Fe2Te3, J. Phys. C Solid State Phys., 1979, 12, p 873879

15. L. Norén, V. Ting, R.L. Withers, and G. van Tendeloo, An Electron and X-Ray Diffraction Investigation of Ni1+xTe2 and $\mathrm{Ni} 1+\mathrm{xSe} 2 \mathrm{CdI} / \mathrm{NiAs}$ Type Solid Solution Phases, J. Solid State Chem., 2001, 161, p 266-273. https://doi.org/10.1006/jssc.2001. 9309

16. C.M. Arvhult, S. Poissonnet, D. Menut, S. Gossé, and C. Guéneau, Thermodynamic Assessment of the Fe-Te System Part I: Experimental Study, J. Alloys Compd., 2019, 773, p 314-326. https://doi.org/10.1016/j.jallcom.2018.09.265

17. G. Brostigen and A. Kjekshus, Compounds with the Marcasite Type Crystal Structure V The Crystal Structures of FeS2, FeTe2 and CoTe2, Acta Chem. Scand., 1970, 24, p 1925-1940

18. W.J. Boettinger, U.R. Kattner, K.W. Moon, and J.H. Perepezko, DTA and Heat-Flux DSC Measurements of Alloy Melting and Freezing, in Methods for Phase Diagram Determination, 2008. https://doi.org/10.1016/b978-008044629-5/50005-7

19. C.M. Arvhult, C. Guéneau, S. Gossé, and M. Selleby, Thermodynamic Assessment of the Fe-Te System. Part II: Thermodynamic Modelling, J. Alloys Compd., 2018, 767, p 883-893. https://doi.org/10.1016/j.jallcom.2018.07.051

20. C.M. Arvhult, C. Guéneau, S. Gossé, and M. Selleby, Thermodynamic Assessment of the Ni-Te System, J. Mater. Sci., 2019, 54(16), p 11304-11319. https://doi.org/10.1007/s10853-01903689-0

21. J.O. Andersson, T. Helander, L. Höglund, P. Shi, and B. Sundman, Thermo-Calc \& DICTRA, Computational Tools for Materials Science, Calphad, 2002, 26, p 273-312. https://doi.org/10. 1016/S0364-5916(02)00037-8

22. H. Ipser, N.L. Komarek, and H. Mikler, Transition Metal-Chaleogen Systems, V. The Iron-Tellurium Phase Diagram, Mon. Chem., 1974, 105, p 1322-1334.

Publisher's Note Springer Nature remains neutral with regard to jurisdictional claims in published maps and institutional affiliations. 